\title{
Bee pollen and propolis improve neuroinflammation and dysbiosis induced by propionic acid, a short chain fatty acid in a rodent model of autism
}

Kawther Aabed ${ }^{1}$, Ramesa Shafi Bhat ${ }^{2}$, Abeer Al-Dbass ${ }^{2}$, Nadine Moubayed ${ }^{3}$, Norah Algahtani ${ }^{4}$, Nada M. Merghani ${ }^{4}$, Azizah Alanazi ${ }^{5}$, Naima Zayed ${ }^{6}$ and Afaf El-Ansary ${ }^{4,6^{*}}$ (i)

\begin{abstract}
Background: Neuroinflammation plays a major role in the pathogenesis of autism because the cytokine levels are typically disturbed in the brain in autistic patients. Prebiotics-rich diet maintains the healthy gut microbiota and hence can regulate the neuroinflammation indirectly. The study aimed to investigate the role of bee pollen and propolis in ameliorating neuroinflammation, including cytokine levels, in an animal model of autism.

Methods: Hamsters were classified as four groups: Group I, control; Group II, autistic model/animals treated with $250 \mathrm{mg}$ propionic acid (PPA)/kg body weight (BW)/day for 3 days; Group III, animals treated with bee pollen at a dose of $250 \mathrm{mg} / \mathrm{kg}$ BW/day for 4 weeks; and Group IV, animals treated with propolis at a dose of $250 \mathrm{mg} / \mathrm{kg}$ BW/ day for 4 weeks. Neuroinflammatory responses were evaluated using the levels of interferon $\gamma$ (IFN- $\gamma$ ), interleukin 1 alpha (IL-1a), IL-6, IL-10, IL-12 (p70), vascular endothelial growth factor (VEGF), and tumor necrosis factor a (TNFa).

Results: Significant decrease of IL-10 $(P<0.026)$, VEGF $(P<0.005)$, and TNFa $(P<0.005)$ levels and increased IL-1a $(P<$ 0.032), IL-6(P<0.028), and IFN- $\gamma(P<0.013)$ levels were observed between the four studied groups. The neurotoxic effects of PPA was clearly presented as much higher IL-6, as pro-inflammatory cytokine $(P<0.05)$, concomitant with much lower IL-10, as anti-inflammatory cytokine $(P<0.015)$ compared to controls. Both bee pollen and propolis were effective in ameliorating the neurotoxic effects of PPA demonstrating non-significant changes of IL-6 and IL-10 when compared to control healthy hamsters.

Conclusions: Our findings indicate that both bee pollen and propolis protect against neuroinflammation in the rodent model of autism. However, further studies are needed to investigate the clinical benefits of prebiotics-rich diet in neurodevelopmental disorders, such as autism.
\end{abstract}

Keywords: Autism, Propionic acid, Cytokines, Neuroinflammation

\section{Background}

Brain pathology in autism as a neurodevelopmental disorder is related to neuroinflammation in different brain parts. Evidence of neuroinflammation in autism includes astrocyte and microglial activation, exclusively increased proinflammatory cytokines [1].

\footnotetext{
* Correspondence: afafkelansary@gmail.com

${ }^{4}$ Central laboratory, Female Centre for Scientific and Medical Studies, King Saud University, Riyadh, Saudi Arabia

${ }^{6}$ Therapeutic Chemistry Department, National Research Centre, Dokki, Cairo, Egypt

Full list of author information is available at the end of the article
}

Animal models of autism are being developed to examine the essential mechanisms, advance medicine, and identify approaches of the evaluation of symptoms of this disorder [2, 3]. Propionic acid (PPA) is an intermediate breakdown product of cellular fatty acids, and it is produced in the gut, along with other short-chain fatty acids such as acetate and butyrate, all of which are major metabolic products of enteric bacteria and are also fermentation products of nutritional carbohydrates and amino acids $[4,5]$. PPA is formed by bacteria in the intestinal tract [4] and oral mucosa [6]. Because PPA is a 
weak organic acid and exists in ionized and non-ionized shapes at physiological $\mathrm{pH}$, it easily crosses the gutblood and blood-brain barriers and reaches the brain [7].

PPA-treated rats have typical autistic features, including hyperlocomotion, impaired social interaction, anxiety, and repetitive behavior [8, 9]. Clostridial species are the main gut colonist in primary life and are producers of PPA and other short-chain fatty acids [10]. Clostridia are resistant to most antibiotics used for frequent infections and are a reason of major hospital-acquired infectious disease [10]. Remarkably, spore-making anaerobes and microaerophilic bacteria mainly from Clostridial species have been demonstrated to be elevated in autistic patients $[11,12]$.

It is well accepted that immune responses can affect the functions of the endocrine and nervous systems. Immuneneuroendocrine network (INEN) is defined as the interactions between immune, nervous, and endocrine systems. The brain gets immune signals from the soluble circulating cytokines (e.g., IL- $1 \alpha$, IL- $1 \beta$, TNF- $\alpha$, and IL-6) transported through the blood-brain barrier (BBB), from peripheral immunity through the vagus nerve, and from immune cells entering the brain and the brain immune microglial cells [13, 14]. Environmental factors that disrupt INEN functions include exposures to microbial, chemical, physical, and psychological stressors. Therefore, PPA, which is a metabolic endproduct of clostridia species and is known to be 10fold higher in individuals with autism, can be regarded as a stressor for both the immune and nervous systems [15].

Bee pollens and propolis are rich in flavonoid, trace elements, and other healthy components, and they have been demonstrated to possess several amazing health effects, such as antioxidant, anti-allergic, and anti-inflammatory properties [16]. In this study, proinflammatory and anti-inflammatory cytokines were investigated in PPA -treated hamsters, and the effectiveness of bee pollen and propolis (two intervention strategies) was also examined.

\section{Methods}

\section{Animals}

Twenty four male golden Syrian hamsters with body weight $(\mathrm{BW})$ between $60 \mathrm{~g}$ and $100 \mathrm{~g}$ were used in this study, and they were bought from a live safari store in Riyadh, Saudi Arabia. Hamsters were raised strictly under a standard laboratory condition and fed on standard pellets. All the hamsters were kept individually in cage $41\left(40 \times 35 \times 20 \mathrm{~cm}^{3}\right)$, with controlled temperature $\left(21 \pm 1^{\circ} \mathrm{C}\right)$ and light conditions (light on at 9:00 AM and light off at 21:00 PM). Hamsters had free access to food (standard laboratory animal feed pellets) and water.

\section{Ethics approval}

The study was approved by Animal Research Committee of Princess Nourah Bint Abdulrahman University, Riyadh (Approval number, IBR- 16-0031). All the methods used in the study strictly followed the guidelines of National Institutes of Health Guide for the Care and treatment of Laboratory Animals in Experiments.

\section{Experimental design}

Hamsters were randomly divided equally into four groups. Group I was assigned as control; Group II (rodent autistic model) was treated with $250 \mathrm{mg} P P A / \mathrm{kg}$ BW/day for 3 days; Group III was fed with bee pollen at a dose of $250 \mathrm{mg} / \mathrm{kg} \mathrm{BW}$ for 25 days after PPA intoxication; Group IV was fed with propolis at the dose of 250 $\mathrm{mg} / \mathrm{kg} \mathrm{BW}$ for 25 days after PPA intoxication. A descriptive diagram for the experimental work is presented in Fig. 1.

\section{Preparation of brain homogenates for identification of cytokines}

At the end of the study, which lasted for 4 weeks, all the animals were sacrificed, and the whole brain was collected. The brain tissue was homogenized with Tissue Lyser LT (QIAGEN) at a high-speed of 50 rotations per minute, and the homogenate was then centrifuged at $4000 \mathrm{rpm}$ for $15 \mathrm{~min}$ before the identification of the specific cytokines.

\section{Quantification of cytokines in the brain tissue}

MILLIPLEX ${ }^{\oplus}$ MAP kit for Mouse Cytokine/Chemokine Magnetic Bead panel was used for quantification of the cytokines in the brain homogenate according to the manufacturer's instruction. A panel of measured cytokines comprised interferon $\gamma($ IFN- $\gamma)$, interleukin 1 alpha (IL-1 $\alpha$ ), IL-6, IL-10, IL-12 (p70), vascular endothelial growth factor (VEGF), and tumor necrosis factor $\alpha$ (TNF- $\alpha$ ).

\section{Identification of $C$. difficile in fecal samples using a toxin assay}

All the fecal samples except those from the bee pollen group were preliminary positive for Clostridium difficile growth, manifesting as yellow colonies with glass texture on CCFA agar plates. C. difficile Quick check (TECH$\mathrm{LAB}$, Alere, USA) was performed according to the manufacturer's instruction for further identification of $C$. difficile in the positive groups.

\section{Statistical analyses}

The data in the present study are expressed as means \pm standard deviation (SD). All statistical comparisons between the control hamster group and the PPA-, bee pollen-, and propolis-treated hamster groups were 


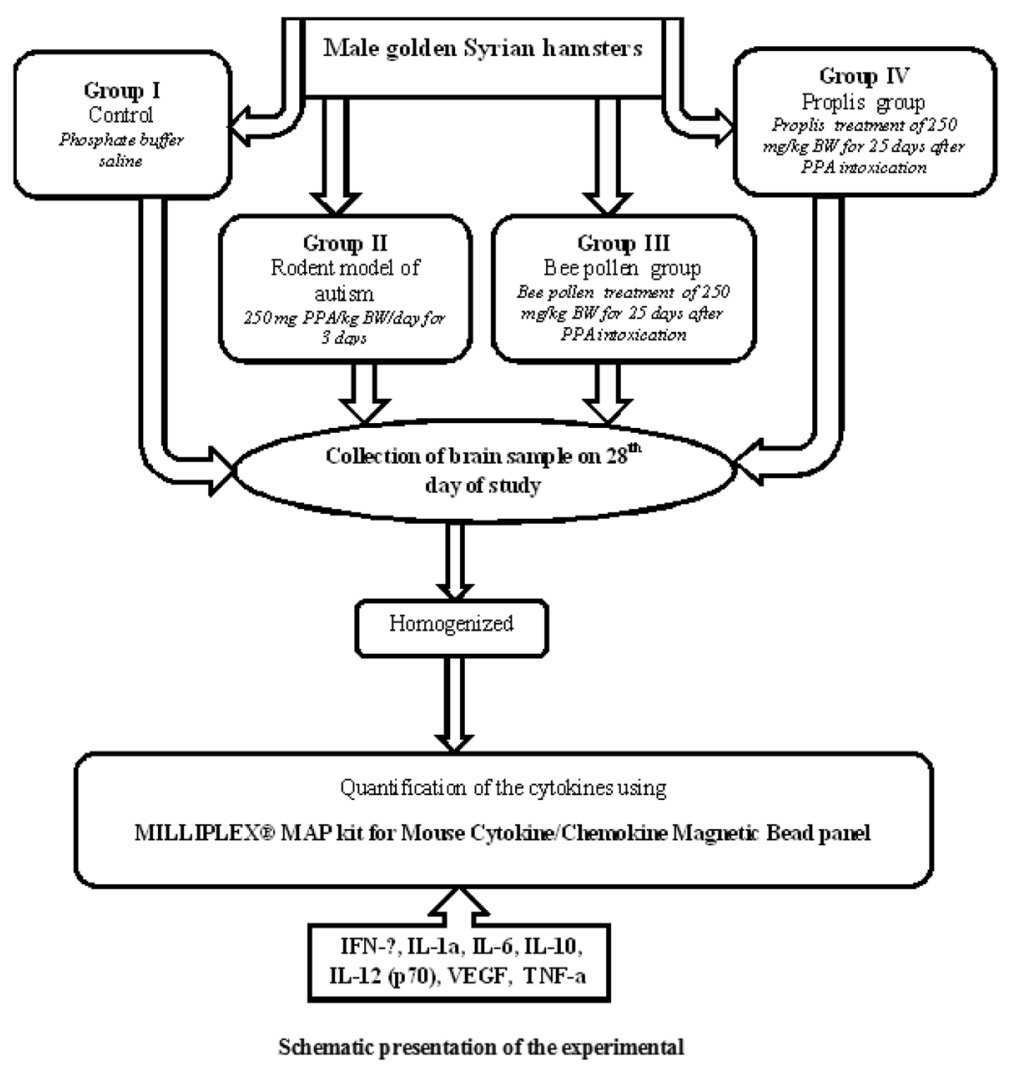

Fig. 1 Diagrammatic presentation of the experimental work

performed using one-way analysis of variance (ANOVA) tests with Dunnett's test for multiple comparisons. Statistical Package for the Social Sciences (SPSS, Chicago, IL, USA) was used. Significance was assigned at a $P$ level of $<0.05$. Receiver operating characteristics curve (ROC) analysis was performed. The area under the curve (AUC), cutoff values, and the degrees of specificity and sensitivity were calculated. Pearson's correlations were performed between the measured parameters. Multiple regression analysis was also performed between the different measured variables.

\section{Results}

Significantly lower levels of IL-10 (64.11\% decrease), VEGF (9.9\%), and TNF $\alpha$ (15.22\%) together with increased IL-1 $\alpha$ (20.33\%), IL-6 (327.03\%), and IFN- $\gamma$ (5.29\%) levels were observed in PPA-treated group compared to controls as shown in Table 1. The neurotoxic effects of PPA was clearly presented as much higher IL-6, as pro-inflammatory cytokine $(\mathrm{P}<0.05)$, together with much lower IL-10, as anti-inflammatory cytokine $(\mathrm{P}<$ 0.015) compared to controls. Both bee pollen and propolis were effective in ameliorating the neurotoxic effects of PPA demonstrating non-significant changes of IL-6 and
IL-10 when compared to control healthy hamsters (Table 1). Table 2 shows the multiple regression analysis of the measured cytokines with IL-12 (P70) (pg/ml) and TNF $\alpha$ $(\mathrm{pg} / \mathrm{ml})$ as dependent variables respectively. The influence of TNF $\alpha$, VEGF, and IL- $1 \alpha$ as independent variables on IL-12 (P70) as dependent variable can be easily observed from the adjusted $R^{2}$. While TNFo alone influences IL-12 with $52.6 \%$, there were a remarkable increase in the influence when combined with VEGF (57.7\%), and with both VEGF, and IL-1 $\alpha$ (63.1\%).

Additionally, IL-12 as predictor variable influences TNF $\alpha$ as dependent variable with $52.6 \%$, and much higher influence was reported for IL-12 and NEGF together as predictor variables $(62.4 \%)$. Table 3 presents the ROC analysis of the measured cytokines in the four studied groups. It can be easily noticed that among the measured cytokines, ILs-6, -10 , and -12 together with TNF $\alpha$ recorded the much higher AUCs as predictive markers of PPA neurotoxicity, and therapeutic effects of bee pollen and propolis. Table 4 shows the presence or absence of $C$. difficile antigen, toxin $\mathrm{A}$, and toxin $\mathrm{B}$ in the four studied groups. $C$. difficile antigen was present in three studied groups, and toxins A and B were not detected in the bee pollen group. 
Table 1 Mean $\pm S$. D of the measured variables in the four studied groups

\begin{tabular}{|c|c|c|c|c|}
\hline Parameters & Groups & Mean \pm S.D. & $P$ value ${ }^{\mathbf{a}}$ & P value ${ }^{\mathbf{b}}$ \\
\hline \multirow[t]{4}{*}{ IFNG (pg/ml) } & Control & $120.70 \pm 167.85$ & & 0.046 \\
\hline & PPA & $127.08 \pm 192.57$ & 1.000 & \\
\hline & Be pollen & $17.05 \pm 26.48$ & 0.024 & \\
\hline & Propolis & $23.23 \pm 22.52$ & 0.337 & \\
\hline \multirow[t]{4}{*}{ IL-1A (pg/ml) } & Control & $181.05 \pm 65.52$ & & 0.035 \\
\hline & PPA & $217.85 \pm 76.89$ & 0.531 & \\
\hline & Be pollen & $116.39 \pm 40.72$ & 0.109 & \\
\hline & Propolis & $168.96 \pm 15.29$ & 0.981 & \\
\hline \multirow[t]{4}{*}{ IL-6 (pg/ml) } & Control & $18.87 \pm 4.69$ & & 0.091 \\
\hline & PPA & $80.56 \pm 63.58$ & 0.050 & \\
\hline & Be pollen & $21.94 \pm 25.93$ & 0.336 & \\
\hline & Propolis & $21.58 \pm 15.36$ & 0.630 & \\
\hline \multirow[t]{4}{*}{ IL-10 (PG/ML) } & Control & $213.86 \pm 212.98$ & & 0.050 \\
\hline & PPA & $76.76 \pm 36.44$ & 0.015 & \\
\hline & Be pollen & $94.08 \pm 28.87$ & 0.022 & \\
\hline & Propolis & $231.39 \pm 270.26$ & 0.572 & \\
\hline \multirow[t]{4}{*}{ IL-12(P70) (pg/ml) } & Control & $82.07 \pm 8.65$ & & 0.094 \\
\hline & PPA & $71.03 \pm 7.57$ & 0.336 & \\
\hline & Be pollen & $70.11 \pm 13.10$ & 0.271 & \\
\hline & Propolis & $69.14 \pm 7.35$ & 0.214 & \\
\hline \multirow[t]{4}{*}{ VEGF (pg/ml) } & Control & $5.95 \pm 2.43$ & & 0.010 \\
\hline & PPA & $5.36 \pm 2.64$ & 0.575 & \\
\hline & Be pollen & $3.58 \pm 0.85$ & 0.025 & \\
\hline & Propolis & $3.41 \pm 0.53$ & 0.010 & \\
\hline \multirow[t]{4}{*}{ TNFA $(\mathrm{pg} / \mathrm{ml})^{c}$} & Control & $17.11 \pm 1.39$ & & 0.003 \\
\hline & PPA & $14.50 \pm 0.91$ & 0.140 & \\
\hline & Be pollen & $13.95 \pm 3.27$ & 0.057 & \\
\hline & Propolis & $11.72 \pm 2.24$ & 0.001 & \\
\hline
\end{tabular}

a $P$ value between each group and the control group

${ }^{b} P$ value among all groups

\section{Discussion}

The present study demonstrates the immune variation of the neurotoxic properties of PPA and the remarkable ameliorating effects of bee pollen and propolis as prebiotics because they can induce the growth of healthy bacteria and reduce the overgrown of pathogenic $C$. difficile (Table 1 and Fig. 2).

This can find support in multiple studies which have investigated the biochemical, physiological, pharmaceutical, and medicinal properties of bee pollen and propolis as poly-phenolic and flavonoids -rich products. It is well known that both demonstrate free radical scavenging activity and multiple pharmaceutical potencies, including anti-inflammatory, immune-modulatory, and antioxidant activity [16].

IL-1 is a pro-inflammatory cytokine and a key mediator in neuronal toxicity and death. Treatment of purified astrocytes or co-cultures of neurons and glial cells with IL-1 usually induces caspase activation and results in neuronal death. Neuronal cell death induced by IL-1 is prevented by pre-treatment with the IL-1 receptor antagonist, caspase inhibitor, or the antioxidant $\alpha$ tocopherol, a component of bee pollen and propolis [16]. The IL-1 expression level dramatically increases in the brain after acute brain insults in rodents [17]. Moreover, it is well known that multiple neuro-inflammatory mediators, which are involved in the etiology of autism, are usually released in response to IL-1 $\alpha$; these mediators include IL- 6 , TNF- $\alpha$, prostaglandins, and cyclooxygenase- $2[18,19]$. Therefore, the $20 \%$ increase of IL- $1 \alpha$ in PPA-treated hamsters (Table 1 and Fig. 2) may indicate the neurotoxic effects of orally administered PPA [8]. The neurotoxic effects are also related to the dramatic increase of IL-6 (a 327.03\% higher level) in PPA-treated animals $(\mathrm{P}<0.05)$.

Multiple studies have demonstrated that IL-6 is functionally linked to the acute phase inflammatory Creactive protein (CRP). During the elevation of IL-6, the

Table 2 Multiple regression analyses using a stepwise method with IL-12 (P70) (pg/ml) and TNFa (pg/ml) as dependent variables

\begin{tabular}{|c|c|c|c|c|c|c|}
\hline \multirow{2}{*}{$\begin{array}{l}\text { Dependent } \\
\text { variables }\end{array}$} & \multirow[t]{2}{*}{ Predictor variables } & \multirow[t]{2}{*}{ Coefficients } & \multirow{2}{*}{$\begin{array}{l}P \\
\text { values }\end{array}$} & \multirow{2}{*}{$\begin{array}{l}\text { Adjusted } \\
\mathrm{R}^{2}\end{array}$} & \multicolumn{2}{|l|}{$95 \% \mathrm{Cls}$} \\
\hline & & & & & Lower & Upper \\
\hline \multirow[t]{6}{*}{ IL-12 (P70) (pg/ml) } & TNFa & 3.454 & 0.000 & 0.526 & 2.227 & 4.681 \\
\hline & TNFa & 3.873 & 0.000 & 0.577 & 2.641 & 5.106 \\
\hline & VEGF & -1.755 & 0.047 & & -3.480 & -0.029 \\
\hline & TNFa & 3.874 & 0.000 & 0.631 & 2.720 & 5.027 \\
\hline & VEGF & -2.143 & 0.013 & & -3.798 & -0.489 \\
\hline & $\mathrm{IL}-1 \mathrm{~A}$ & 0.056 & 0.035 & & 0.004 & 0.108 \\
\hline \multirow[t]{3}{*}{ TNFa (pg/ml) } & IL-12 (P70) (pg/ml) & 0.157 & 0.000 & 0.526 & 0.101 & 0.213 \\
\hline & IL-12 (P70) (pg/ml) & 0.157 & 0.000 & 0.624 & 0.107 & 0.206 \\
\hline & VEGF (pg/ml) & 0.459 & 0.008 & & 0.132 & 0.786 \\
\hline
\end{tabular}


Table 3 ROC-Curve of various parameters in all groups

\begin{tabular}{|c|c|c|c|c|c|c|c|}
\hline Parameters & Groups & AUC & Cut-off value & Sensitivity \% & Specificity \% & $P$ value & $95 \% \mathrm{Cl}$ \\
\hline \multirow[t]{3}{*}{ IFN- $\gamma(\mathrm{pg} / \mathrm{ml})$} & PPA & 0.500 & 25.380 & $50.0 \%$ & $66.7 \%$ & 1.000 & $0.153-0.847$ \\
\hline & Bee pollen & 0.889 & 8.445 & $83.3 \%$ & $100.0 \%$ & 0.025 & $0.673-1.105$ \\
\hline & Propolis & 0.667 & 17.380 & $83.3 \%$ & $66.7 \%$ & 0.337 & $0.331-1.002$ \\
\hline \multirow[t]{3}{*}{ IL-1A (pg/ml) } & PPA & 0.694 & 172.545 & $66.7 \%$ & $66.7 \%$ & 0.262 & $0.385-1.004$ \\
\hline & Bee pollen & 0.861 & 129.458 & $66.7 \%$ & $100.0 \%$ & 0.037 & $0.645-1.077$ \\
\hline & Propolis & 0.569 & 152.360 & $83.3 \%$ & $50.0 \%$ & 0.689 & $0.210-0.928$ \\
\hline \multirow[t]{3}{*}{ IL-6 (pg/ml) } & PPA & 0.833 & 23.195 & $83.3 \%$ & $83.3 \%$ & 0.055 & $0.570-1.096$ \\
\hline & Bee pollen & 0.667 & 16.880 & $66.7 \%$ & $83.3 \%$ & 0.337 & $0.317-1.017$ \\
\hline & Propolis & 0.583 & 18.145 & $66.7 \%$ & $66.7 \%$ & 0.631 & $0.241-0.926$ \\
\hline \multirow[t]{3}{*}{ IL-10 (PG/ML) } & PPA & 0.917 & 122.270 & $100.0 \%$ & $83.3 \%$ & 0.016 & $0.742-1.091$ \\
\hline & Bee pollen & 0.889 & 119.215 & $100.0 \%$ & $83.3 \%$ & 0.025 & $0.673-1.105$ \\
\hline & Propolis & 0.597 & 122.055 & $66.7 \%$ & $83.3 \%$ & 0.575 & $0.239-0.956$ \\
\hline \multirow[t]{3}{*}{ IL-12 (P70) (pg/ml) } & PPA & 0.833 & 72.835 & $66.7 \%$ & $100.0 \%$ & 0.055 & $0.593-1.073$ \\
\hline & Bee pollen & 0.861 & 72.130 & $83.3 \%$ & $100.0 \%$ & 0.037 & $0.604-1.119$ \\
\hline & Propolis & 0.903 & 72.130 & $83.3 \%$ & $100.0 \%$ & 0.020 & $0.708-1.098$ \\
\hline \multirow[t]{3}{*}{ VEGF (pg/ml) } & PPA & 0.597 & 4.500 & $66.7 \%$ & $66.7 \%$ & 0.575 & $0.253-0.941$ \\
\hline & Bee pollen & 0.889 & 4.240 & $83.3 \%$ & $83.3 \%$ & 0.025 & $0.697-1.081$ \\
\hline & Propolis & 0.944 & 3.645 & $83.3 \%$ & $100.0 \%$ & 0.010 & $0.814-1.075$ \\
\hline \multirow[t]{3}{*}{ TNFa (pg/ml) } & PPA & 0.944 & 15.095 & $83.3 \%$ & $100.0 \%$ & 0.010 & $0.814-1.075$ \\
\hline & Bee pollen & 0.833 & 14.845 & $83.3 \%$ & $100.0 \%$ & 0.055 & $0.535-1.132$ \\
\hline & Propolis & 1.000 & 14.680 & $100.0 \%$ & $100.0 \%$ & 0.004 & $1.000-1.000$ \\
\hline
\end{tabular}

ROC, receiver operating characteristics curve; AUC, area under the curve; IFN- $\gamma$, interferon $\gamma$

pro-inflammatory cytokines, including IL- 1 and TNF- $\alpha$, promote the expression of CRP. The neurotoxic effects of PPA, manifesting as the remarkable increase in IL- $1 \alpha$ and IL-6, were clearly observed in this study (Table 1 ). Notably, both IL- 6 and CRP levels are elevated in the plasma in the individuals with autism. The findings are supported by those in a recent study by Sharma, in which PPA-treated animals showed enhanced inflammation, manifesting as increased IL- 6 and TNF- $\alpha$ and decreased interleukin-10, in different brain regions [9].

Interleukin-10, an anti-inflammatory cytokine, exerts a surplus of immunomodulatory functions during an inflammatory response. It is initially defined as a

Table 4 Identification of $C$. difficille by a toxin assay

\begin{tabular}{lllll}
\hline Fecal samples & Antigen & Toxin A & Toxin B & C. difficile \\
\hline PPA & + & + & + & + \\
Bee pollen & - & - & - & - \\
Propolis & + & - & - & + \\
C. difficile & + & & & +
\end{tabular}

Antigen, glutamate dehydrogenase antigen; PPA, propionic acid; +, positive; - , negative

If Antigen is positive and toxins $A$ and $B$ are negative, non-toxin-producing $C$. difficile is present

If Antigen, toxin A, and toxin B are positive, toxin-producing C. difficile is present proinflammatory cytokine synthesis inhibitory factor, retards inflammation by reducing cytokine receptor expression and inhibiting receptor activation [20]. Therefore, the significant decrease in IL-10 and the significant increase in IL-6 clearly suggest the neurotoxic effects of PPA (Table 1 and Figs. 2 and 3).

Prebiotics, such as dietary fibers and some oligosaccharides, have been shown to have beneficial effects on human health [21]. It has been widely demonstrated that ingestion of prebiotics is associated with changes in gut microbes. For example, a 10-fold increase in fecal Bifidobacteria has been demonstrated in participants receiving oligosaccharides compared with those receiving placebos [22]. Recently, bee pollen from Saudi Arabian origin has been found to be rich in oligosaccharides, which can induce a remarkable reduction in the Clostridia species [23, 24].

Bee therapy or apitherapy is the use of honey bee products for therapeutic purposes. Bee pollen and propolis are among the medicinal products of the bee. The neuroinflammation process involves the release of cytokines (immune mediators) from neurons or damaged tissues. Table 1 shows the therapeutic effect of bee pollen and propolis, and it can be easily noticed that bee pollen and propolis have anti-inflammatory effects, 


\section{Mean}

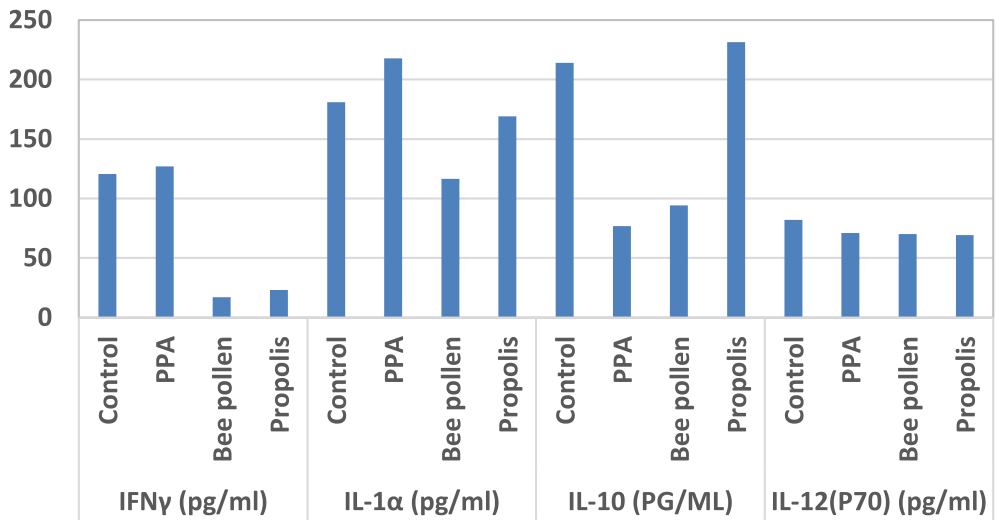

Mean

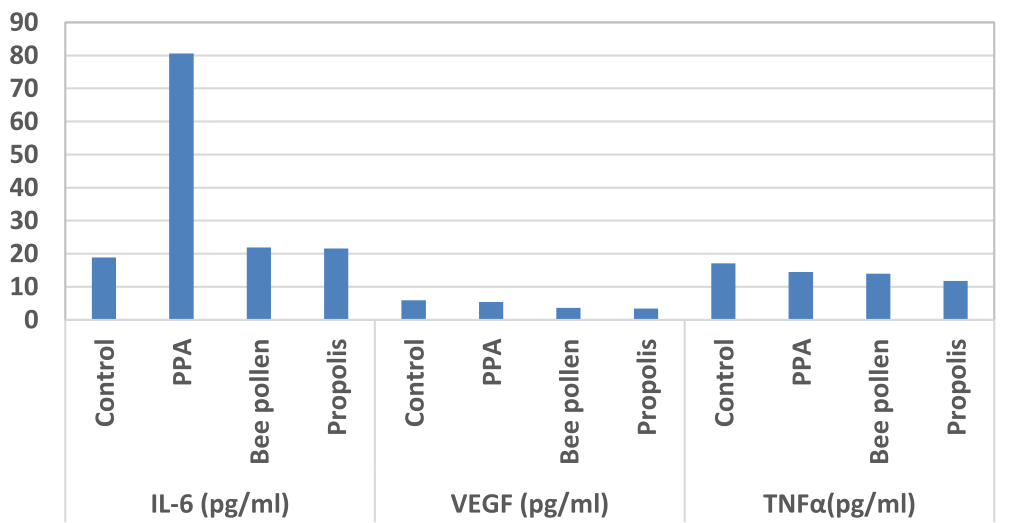

Fig. 2 Mean of the measured cytokines in the four studied groups

manifesting as remarkable decreases in IFN- $\gamma$, IL- $1 \alpha$, Il6, VEGF, and TNF- $\alpha$ and a significant increase in IL-10, an anti-inflammatory cytokine. These findings are consistent with those in one previous study by Hegazi [25], which indicates that bee pollen and propolis contain active substances in the floral origin of honey bee and plants, and these active substances can act upon both innate and adaptive immune responses. These compounds decrease pro-inflammatory cytokine synthesis and superoxide anion production in rabbit neutrophils. However, the activity of bee pollen is relatively lower than that of propolis, especially in terms of the induction of IL-10, an anti-inflammatory cytokine; this might be because of the higher amount of polyphenols, which are anti-oxidant and anti-inflammatory compounds, in propolis than in bee pollen [26].

Angiogenesis, an accepted mechanism in gutmicrobiota related inflammation, is critically required for mucosal remodeling during treatment [27]. Therefore, the significant decrease in VEGF in bee pollen and propolis-treated groups suggests that the therapeutic effects of both might be mostly through the gut-brain axis.
Neutralization of pathogenic bacterial overgrowth and partial correction of the impaired intestinal hostpathogen interaction (Table 4) can ameliorate the neurotoxic effect of PPA (impaired cytokines) [28].

As demonstrated by DeGrandi et al. between [29], the present study indicates that bee pollen is enriched in bactericidal combinations, as well as carbohydrates and lactic acid, and these ingredients are potent in reducing the growth of microorganisms, among which microbial species, including C. difficile, Klebsiella pneumonia types, and the Candida albicans, are known to be high in autistic patients compared with control healthy individuals [10-12].

Both glutamate excitotoxicity and neuroinflammation are well-known etiological mechanisms of several neurodevelopmental disorders, including autism, and it is suggested that decreased glutamate uptake by astrocytes could result from local inflammation [30]. Multiple studies have demonstrated that increases in IL-6 and IL-1 and a decrease in IL-10 are involved in the cellular mechanisms underlying upregulation of excitatory glutamatergic transmission and downregulation of inhibitory 


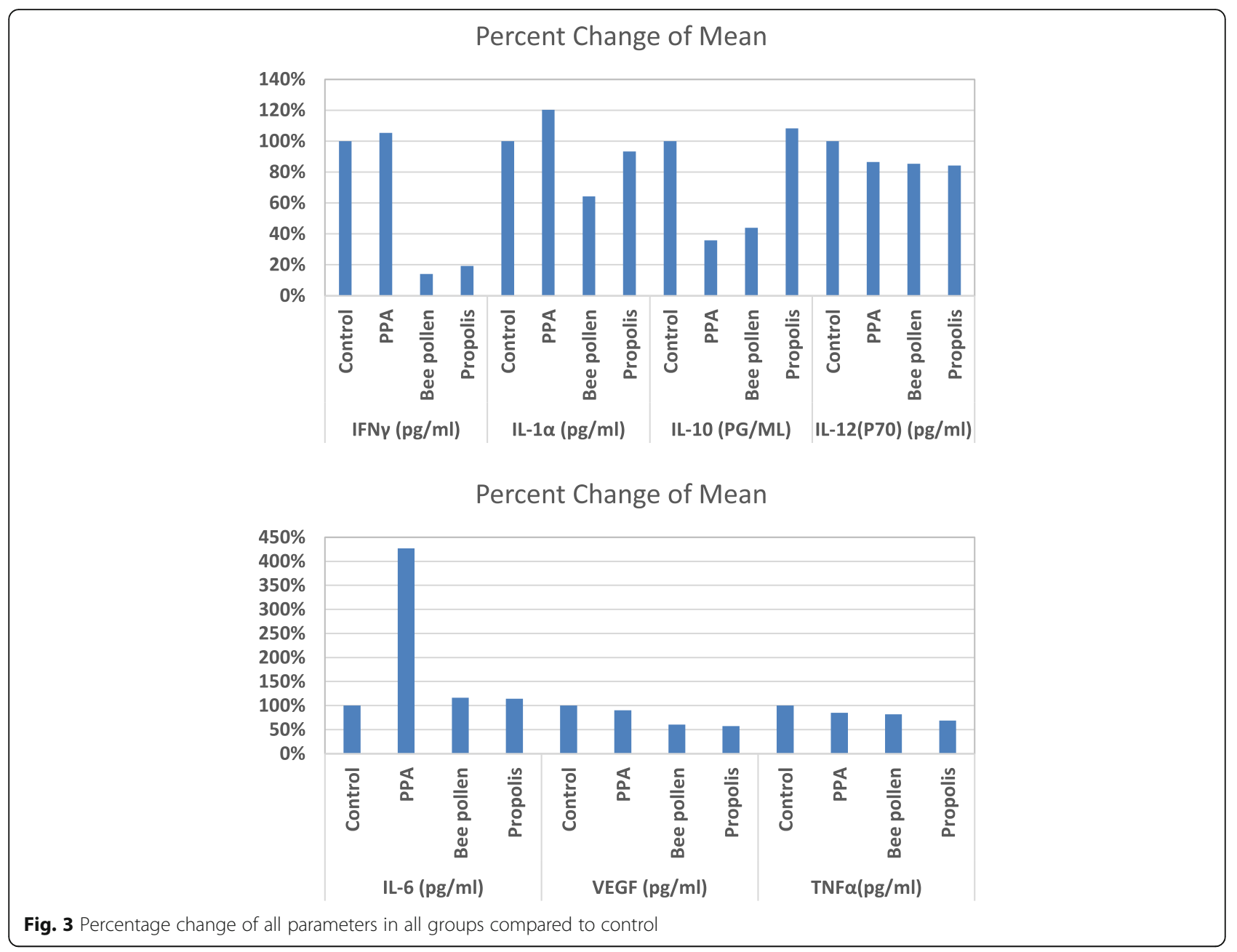

GABAergic transmission [31, 32]. Therefore, the remarkable alterations of these cytokines in response to PPA treatment and the significant amelioration of the alterations observed after bee pollen and propolis treatments highlight the importance of neuroinflammation and glutamate excitotoxicity as two inter-related signaling pathways, which should be targeted as therapeutic strategies of PPA neurotoxicity in rodent models of autism. The speculation can be supported by the findings in our recent study, in which bee pollen was effective in ameliorating the glutamate excitotoxicity and the impaired glutamine-glutamate-GABA circuit, two etiological mechanisms in PPA-induced neurotoxicity.

The reported pollen's anti-inflammatory effect could be easily attributed to the presence of flavonoids, fatty acids, and phytosterols. Pollen is also rich with quercetin, which inhibits the cascade of arachidonic acid metabolism, decreasing the level of pro-inflammatory prostaglandins, having an anti-inflammatory effect [33]. On the other, hand, propolis is rich in cinnamic acid, pcoumaric acid, caffeic acid, ferulic acid, as phenolic compounds, and monoterpenes and sesquiterpenes as terpenoids with potent anti-inflammatory and antinociceptive activities [34].

\section{Conclusions}

The present study ascertains the neuro-inflammatory effects of PPA, and the findings suggest that bee pollen and propolis supplementation reduces the inflammatory response and endotoxemia by ameliorating dysbiosis in hamsters. However further studies on the mechanisms involved in apitherapeutic intervention should be encouraged.

\section{Abbreviations}

AUC: Area under the curv; BBB: Blood-brain barrier; BW: Body weight; CRP: Creactive protein; GP130: Glycoprotein 130; IFN- : Interferon $\gamma$; INEN: Immuneneuroendocrine network; PPA: Propionic acid; STAT3: Signal transducer and activator, transcription 3; TNFa: Tumor necrosis factor a; VEGF: Vascular endothelial growth factor

\section{Acknowledgments}

This research project was supported by the Deanship of Scientific Research, Princess Nourah Bint Abdulrahman University, Grant number RGP-1441-0027. The authors thank the Deanship of Scientific Research and RSSU at King Saud University for the technical support. 


\section{Authors' contribution}

KA, Suggested the microbiology work and codrafted the manuscript; RS, Co drafted the Manuscript; AD, Acquisition of data; NM, Acquisition of the microbiology data; NA, Acquisition of data; NM, Performed the statistical analysis; AA, Acquisition of data; NZ, Codrafted the manuscript AE, Suggested the topic and drafted the manuscript. All authors read and approved the final manuscript.

\section{Funding}

This research project was supported by the Deanship of Scientific Research, Princess Nourah Bint Abdulrahman University, Grant number RGP-1441-0027.

\section{Availability of data and materials}

Raw data can be available on request.

\section{Ethics approval and consent to participate}

All procedures performed were in accordance with the ethical standards of the institutional and/or national research committee and with the 1964 Helsinki declaration and its later amendments or comparable ethical standards.

\section{Consent for publication}

All authors have read the manuscript and agreed for the submission.

\section{Competing interests}

The authors declare that they have no competing interests.

\section{Author details}

'Biology Department, College of Science, Princess Nourah Bint Abdulrahman University, Riyadh, Saudi Arabia. ${ }^{2}$ Biochemistry Department, College of Sciences, King Saud University, Riyadh, Saudi Arabia. 'Biology Department, College of Sciences, King Saud University, Riyadh, Saudi Arabia. ${ }^{4}$ Central laboratory, Female Centre for Scientific and Medical Studies, King Saud University, Riyadh, Saudi Arabia. ${ }^{5}$ Department of Cell Biology, King Faisal Specialist Hospital and Research Centre, Riyadh, Saudi Arabia. ${ }^{6}$ Therapeutic Chemistry Department, National Research Centre, Dokki, Cairo, Egypt.

Received: 23 May 2019 Accepted: 7 November 2019

Published online: 16 November 2019

\section{References}

1. Kern JK, Geier DA, Sykes LK, Geier MR. Relevance of neuroinflammation and encephalitis in autism. Front Cell Neurosci. 2016;9:519. https://doi.org/10. 3389/fncel.2015.00519.

2. Hrabovska SV, Salyha YT. Animal models of autism spectrum disorders and behavioral techniques of their examination. Neurophysiology. 2016;48:3808. https://doi.org/10.1007/s11062-017-9613-2.

3. Cryan JF, Holmes A. The ascent of mouse: advances in modelling human depression and anxiety. Nat Rev Drug Discov. 2005;4(9):775-90.

4. Jan G, Belzacq AS, Haouzi D, Rouault A, Métivier D, Kroemer G, et al. Propionibacteria induce apoptosis of colorectal carcinoma cells via shortchain fatty acids acting on mitochondria. Cell Death Differ. 2002;9:179-88.

5. Al-Lahham SH, Peppelenbosch MP, Rolfson H, Vonk RJ, Venema K. Biological effects of propionic acid in humans; metabolism, potential applications and underlying mechanisms. Biochim Biophys Acta. 1801;2010:1175-83.

6. Borgstrom MK, Edwardsson S, Svensater G, Twetman S. Acid formation in sucrose exposed dental plaque in relation to caries incidence in schoolchildren. Clin Oral Investig. 2000:4:9-12.

7. Karuri AR, Dobrowsky E, Tannock IF. Selective cellular acidification and toxicity of weak organic acids in an acidic microenvironment. $\mathrm{Br} J$ Cancer. 1993;68:1080-7.

8. El-Ansary AK, Ben Bacha A, Kotb M. Etiology of autistic features: the persisting neurotoxic effects of propionic acid. J Neuroinflammation. 2012;9: 74. https://doi.org/10.1186/1742-2094-9-74.

9. Mirza R, Sharma B. Selective modulator of peroxisome proliferator-activated receptor-a protectspropionic acid induced autism-like phenotypes in rats. Life Sci. 2018. https://doi.org/10.1016/j.lfs.2018.10.045.

10. Stackebrandt E, Rainey FA. Phylogenetic relationships. In: Rood JI, McClane BA, Songer JG, Titball RW. The clostridia, molecular biology and pathogenesis. Academic Press. 1997; 3-19.
11. Song Y, Liu C, Finegold SM. Real-time PCR quantification of clostridia in feces of autistic children. Appl Environ Microbiol. 2004;70:6459-65.

12. Finegold SM, Dowd SE, Gontcharova V, Liu C, Henley KE, Wolcott RD, et al. Pyrosequencing study of fecal microflora of autistic and control children. Anaerobe. 2010;16:444-53.

13. Masi A, Glozier N, Dale R, Guastella AJ. The immune system, cytokines, and biomarkers in autism spectrum disorder. Neurosci Bull. 2017;33:194-204. https://doi.org/10.1007/s12264-017-0103-8.

14. Filiano AJ, Gadani SP, Kipnis J. Interactions of innate and adaptive immunity in brain development and function. Brain Res. 1617;2015:18-27.

15. Dantzer R. Cytokine, sickness behavior, and depression. Immunol Allergy Clin N Am. 2009;29:247-64.

16. Li QQ, Wang K, Marcucci MC, Helena CA, Sawaya F, Hu L, et al. Nutrient-rich bee pollen: A treasure trove of active natural metabolites. J Funct Foods. 2018;19:472-84.

17. Allan SM, Tyrrell PJ, Rothwell NJ. Interleukin-1 and neuronal injury. Nat Rev Immunol. 2005;5:629-40

18. Aleksandrova NP, Danilova GA, Aleksandrov VG. Cyclooxygenase pathway in modulation of the ventilatory response to hypercapnia by interleukin-1 $\beta$ in rats. Respir Physiol Neurobiol. 2015;209:85-90.

19. El-Ansary A, Al-Ayadhi L. GABAergic/glutamatergic imbalance relative to excessive neuroinflammation in autism spectrum disorders. J Neuroinflammation. 2014:11:189.

20. Strle K, Zhou JH, Shen WH, Broussard SR, Johnson RW, Freund GG, et al. Interleukin-10 in the brain. Crit Rev Immunol. 2001;21:427-49. https://doi. org/10.1615/CritRevlmmunol.v21.i5.20.

21. Osborn DA, Sinn JK. Prebiotics in infants for prevention of allergic disease and food hypersensitivity. Cochrane Database Syst Rev. 2007;4:CD006475.

22. Kleessen B, Sykura B, Zunft HJ, Blaut M. Effects of inulin and lactose on fecal microflora, microbial activity, and bowel habit in elderly constipated persons. Am J Clin Nutr. 1997;65:1397-402.

23. Taha EKA. Chemical composition and amounts of mineral elements in honeybeecollected pollen in relation to botanical origin. J Apic Sci. 2015;59:75-81.

24. Ares AM, Valverde S, Bernal JL, Nozal MJ, Bernal J. Extraction and determination of bioactive compounds from bee pollen. J Pharm Biomed Anal. 2018:147:110-24.

25. Hegazi AG. Role of cytokines in Apitherapy. J Clin Cell Immunol. 2015;6:5.

26. Silva JC, Rodrigues S, Feás $X$, Estevinho LM. Antimicrobial activity, phenolic profile and role in the inflammation of própolis. Food Chem Toxicol. 2012;50:1790-5.

27. Rothwell N. Interleukin-1 and neuronal injury: mechanisms, modification, and therapeutic potential. Brain Behav Immun. 2003;17:152-7.

28. Roquetto AR, Monteiro NES, Moura CS, Toreti VC, de Pace F, Santos AD, et al. Green propolis modulates gut microbiota, reduces endotoxemia and expression of TLR4 pathway in mice fed a high-fat diet. Food Res Int. 2015;76:796-803.

29. DeGrandi-Hoffman G, Gage SL, Corby-Harris V, Carroll M, Chambers M, Graham H, Watkins deJong E, Hidalgo G, Calle S, Azzouz-Olden F, Meador C, Snyder L, Ziolkowski N. Connecting the nutrient composition of seasonal pollens with changing nutritional needs of honey bee (Apis mellifera L.) colonies. J Insect Physiol. 2018 Aug Sep;109:114-124.

30. Cartmell T, Ball C, Bristow AF, Mitchell D, Poole S. Endogenous interleukin-10 is required for the defervescence of fever evoked by local lipopolysaccharide-induced and Staphylococcus aureus-induced inflammation in rats. J Physiol. 2003;549:653-64.

31. Conti B, Tabarean I, Andrei C, Bartfai T. Cytokines and fever. Front Biosci. 2004;9:1433-49.

32. Galic MA, Riazi K, Pittman QJ. Cytokines and brain excitability. Front Neuroendocrinol. 2012;33:116-25.

33. Denisow B, Denisow-Pietrzyk M. Biological and therapeutic properties of bee pollen: a review. J Sci Food Agric. 2016;96(13):4303.

34. Parandin R, Daroogari S. Anti-inflammatory and Antinociceptive activities of the Ethanolic extract of Propolis in male mice and rats. Zahedan J Res Med Sci. 2019;21(2):e84150.

\section{Publisher's Note}

Springer Nature remains neutral with regard to jurisdictional claims in published maps and institutional affiliations. 